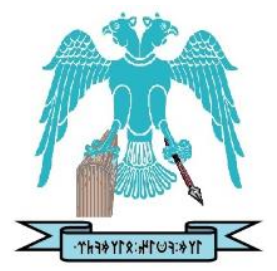

JOURNAL OF ENERGY SYSTEMS

$2020,4(2)$

\title{
Monitoring parameters of power transformers in the electrical power system through smart devices
}

\author{
Vezir Rexhepi \\ University of Pristina, Faculty of Electrical and Computer Engineering, 1000, Sunny Hill, n. n, Pristina, \\ Kosovo, vezir.rexhepi@uni-pr.edu \\ Astrit Hulaj \\ University of Pristina, Faculty of Mechanical Engineering, Department of Mechatronics, 1000, Sunny Hill, n. \\ n, Pristina, Kosovo, astrit.hulaj@uni-pr.edu
}

\begin{abstract}
Nowadays the advancement of technology and equipment to monitor the operating performance of power transformer has achieved a high level. So, the monitoring system enables the continued investigation of the operational work of power transformer parameters as well as the prevention of failures and enhance reliability. However, the monitoring of power transformers is of unquestionable value for the electrical power systems and consumers to have more reliability in supplying. Therefore, given that monitoring involves a considerable number of parameters and elements of transformers, in the present case the overview of the monitoring of some of the most important parameters has been taken into account. Thus, the paper includes the monitoring parameters such as; partial discharges, oil and winding temperatures, bushing currents, tap changer, moisture and dissolved gas analysis. Also, in the paper are presented data for the operation of these parameters in different periods as well as with different loading regimes. The reports of events that correspond to the operational performance of the transformer, which are a good cause for diagnosis and preliminary actions in transformers, are also presented.
\end{abstract}

\section{Keywords: Diagnosis, Electrical power system, Online monitoring, Sensors, Transformer monitoring}




\section{INTRODUCTION}

Advancing the monitoring of power systems, respectively the main elements such as generators, transformers, lines and substations, is essential to their operation and safety. So, today many applications are used which enable a more sophisticated approach and diagnosis for power systems.

Expect of other methods fault diagnosis and condition monitoring issues are nowadays used with intelligent algorithms to predict unwanted breakdowns. There are model-based approaches that using Supervisory Control and Data Acquisition (SCADA). Also, expert systems are one of the essential novel condition monitoring $(\mathrm{CM})$ methodologies to identify and predict faults [1].

As known that power transformers belong to the most valuable assets in electrical power networks. Also, outage impacts of the network, respectively transformers are associated with financial penalties for the power systems can be considerably high [2]. Therefore, the knowledge of the other important parameters such as temperature, DGA, PD, OLTC or moisture is high interest. Moreover, all this information is useful, among other things, in the safety of the operation of the transformer to prevent unplanned outages, which also helps to meet the competitive conditions in the liberalized energy market [3]. To increase the availability and optimize operating management online condition monitoring of power transformers is useful and necessary. So, the task of online monitoring is then to provide focused, purposeful diagnosis information, so that remedial measures can be initiated if needed should fault occur during operation [4]. Monitoring systems also provide the necessary data to make diagnoses and analyses in different working conditions and modes enabling acquaintance with the behavior of transformer parameters and their impacts on the more efficient operation [5]. Monitoring covers the measurement of basic parameters with threshold alarms. So, integration and collection of data from local control functions and early warning of incipient failure symptoms are necessary. This provides the first alert of the transformer has exceeded a previously established threshold value [6]. In addition to the aspect of the safer supply of the consumers, the cost of unplanned maintenance of transformers in case of unforeseen faults should be taken into account, so monitoring through smart devices will help reduce this cost. Thus, benefits will be significant and necessary for the safest operation of transformers in the power system.

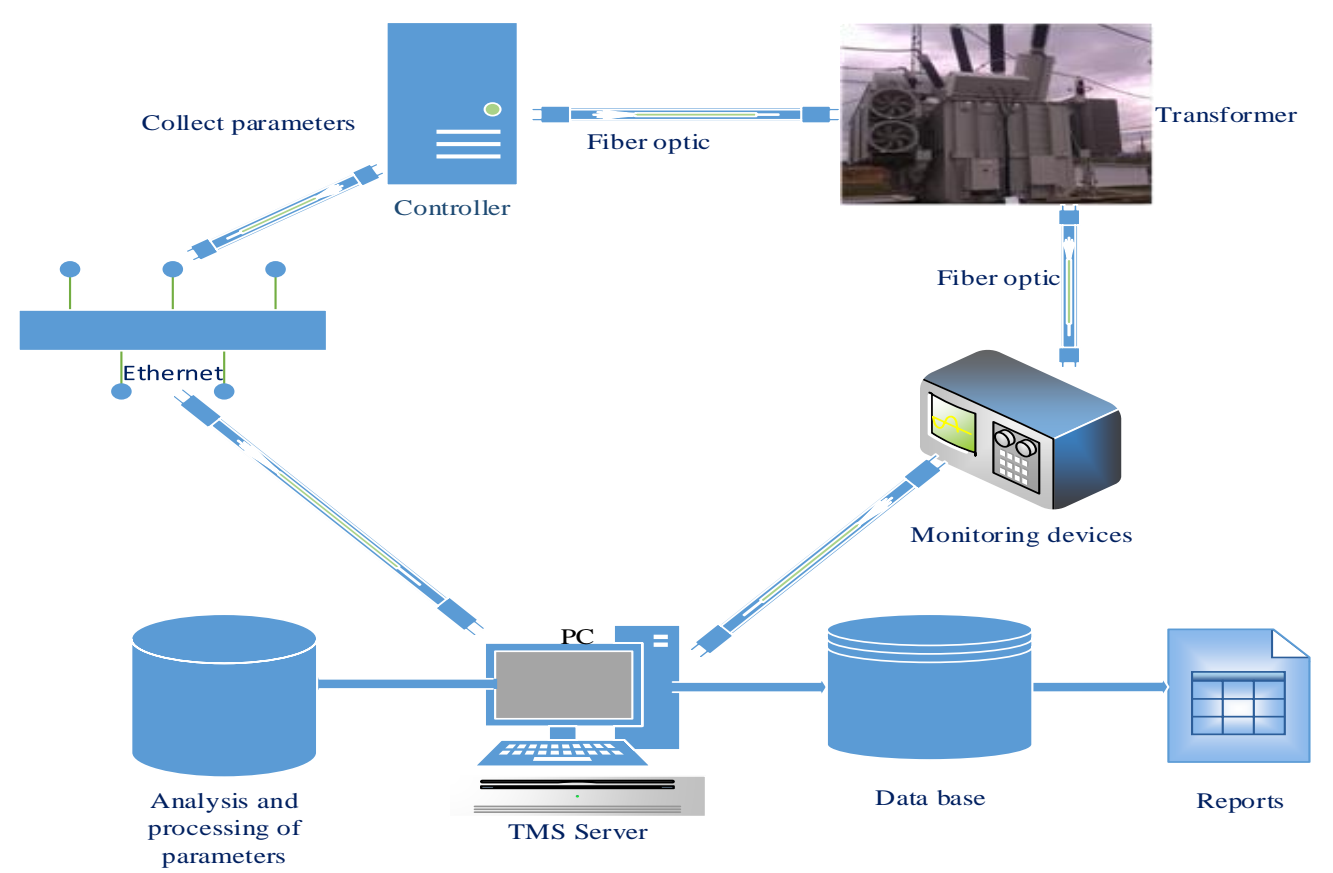

Figure 1. The architecture of the devices in the power transformer monitoring at SS Ferizaj 2 400/110 kV 
Figure 1 describes the structure and chain of equipment and technical aspects of transformer monitoring so that the processing of results and diagnosis is ongoing and online to see and analyze the symptoms of potential faults.

Such smart structure devices help to recognize the operation of transformer equipment and, among other things, affect the safety and diagnosis of its operating parameters. It should be noted that the assessment of the state of electrical, thermal, and mechanical parameters is one of the main elements for defining possible defects in transformers [7].

\section{ONLINE MONITORING OF POWER TRANSFORMER PARAMETERS}

In substation of the power system of Kosovo, respectively in SS Ferizaj $2400 / 110 \mathrm{kV}$ is installed the monitoring system by Koncar. The transformer monitoring system (TMS) consists of hardware and software applications. In the installed hardware from the server room's local SCADA controller installed in the transformer where communication is done via the link Ethernet TCP / IP [8]. Based on this internet protocol, the real-time transfer of information and images regarding the real condition of the transformers has been carried out. These images have been sent to the monitoring center for more detailed analysis [9] [10]. In the controller is installed - origin acquires power supply information and data from sensors and forwards to the server. So one of the many transformer monitoring systems is the Koncar monitoring system (Figure 2). To increase availability and to achieve optimized operating management on-line condition monitoring for power transformers is useful and necessary [11]. Modern and smart devices significantly increase security and facilitate the control and diagnosis of transformers [12]. The life of the transformer is mainly shortened by the deterioration of its auxiliary parts, so about $50 \%$ of the defects are from these devices, while $20 \%$ is from the failure of the insulation system [13].

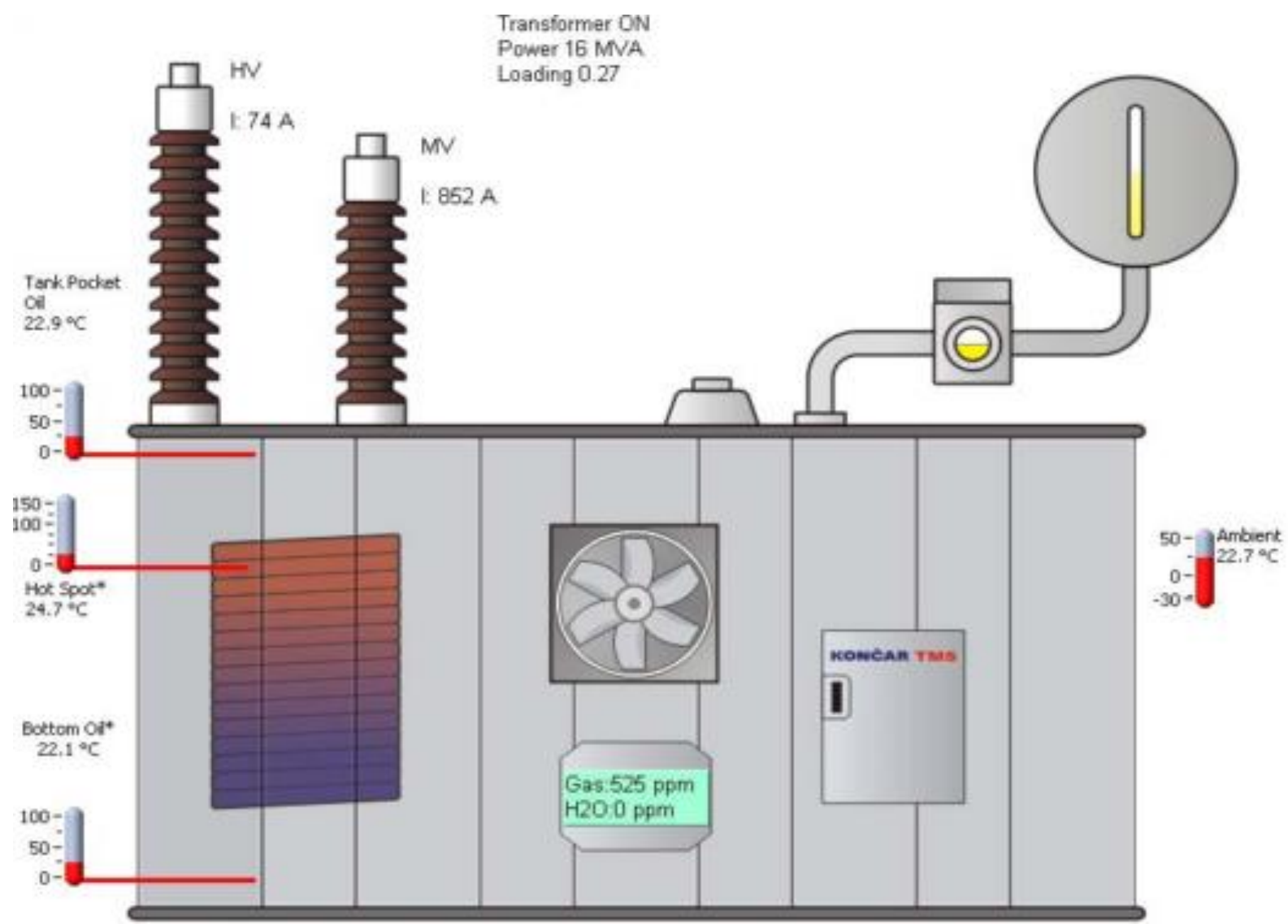

Figure 2. Transformer monitoring system at SS Ferizaj $2400 / 110 \mathrm{kV}$, power transformer 300MVA, (TMS produced by Koncar) 


\subsection{Temperature Monitoring}

The winding temperature is an essential measured parameter in power transformers, which defines the condition and load capacity. Also, the temperature is the primary criterion which limits the transformer life span, and partly the capacity of the transformer to dissipate the heat generated inside the environment. Therefore, information about transformer thermal behavior can bring the improvement of using power transformers. Therefore, certain fast developing failures can be diagnosed and analysis through an online comparison of a measured, such as winding temperature [14].

In Figure 3 are shown the trends of the hot spot, top oil and ambient temperature of power transformer 300 MVA at SS Ferizaj $2440 / 110 \mathrm{kV}(01 / 082015$ - 07/08/2015). So the proper operation and duration of operation of transformers is also in function of the temperature of the windings, tank, tap changer and other accompanying equipment. An overview of the temperature trend, respectively; hot spots in the winding, the temperature of the oil and the environment, is shown in Figure 3, where their superposition increases the temperature level in the coils and thus their damage.

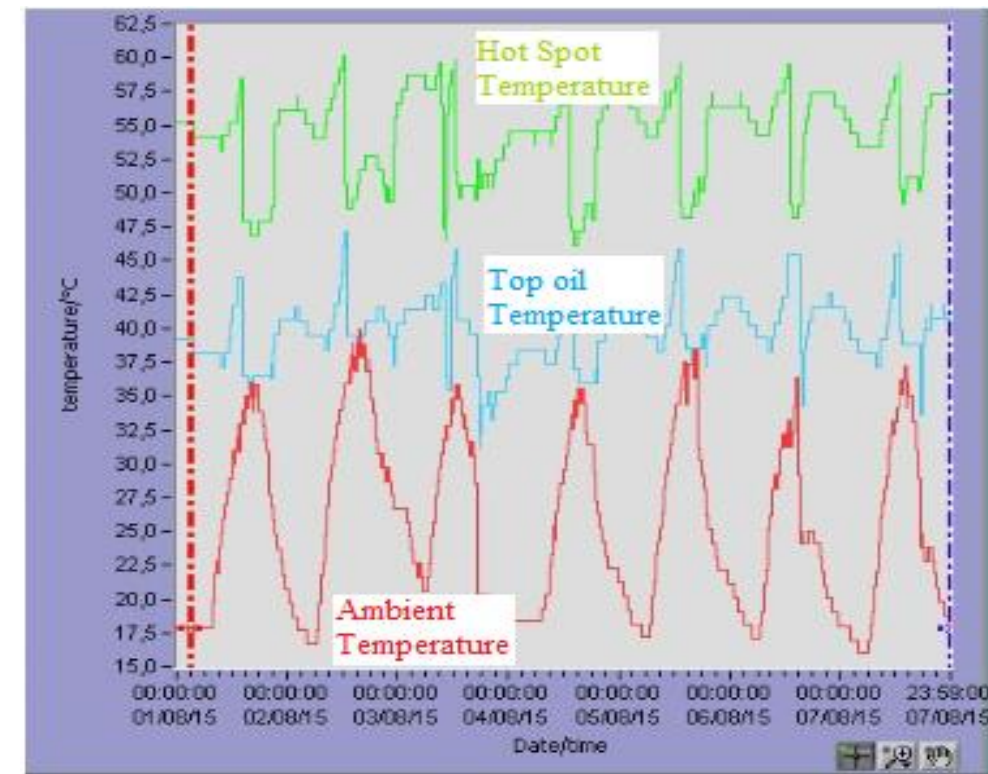

Figure 3. The trend of the hot spot, top oil and ambient temperature of power transformer 300 MVA at SS Ferizaj 2 440/110 kV (01/082015-07/08/2015)

\subsection{Dissolved Gas Analysis}

During the operational work and mainly of the faults in the power transformers different gases are generated. By taking samples of the mineral oil inside a transformer with offline method, one can determine what gases are present and their concentration levels [15].

However, the online monitoring method of gas dissolved is a very important method in finding the causes and their impact on dielectric strength. Therefore, based on the importance of this gas monitoring, in Figure 4 is presented dissolved gas monitoring. From Figure 4, it can be seen that in the winter period January/ February 2016, the gas level has exceeded the limits set according to the standards, respectively the first level $250 \mathrm{ppm}$ and the second level of $500 \mathrm{ppm}$.

This parameter plays a significant role in the operating work of the transformer and provides an overview of the health of the transformer. Also, monitoring such a parameter helps to prevent defects and prepare plans for maintenance and planned interventions in certain parts of the transformer, also is necessary to build a database to make analysis for the types of gases and operational condition of the power transformers. 


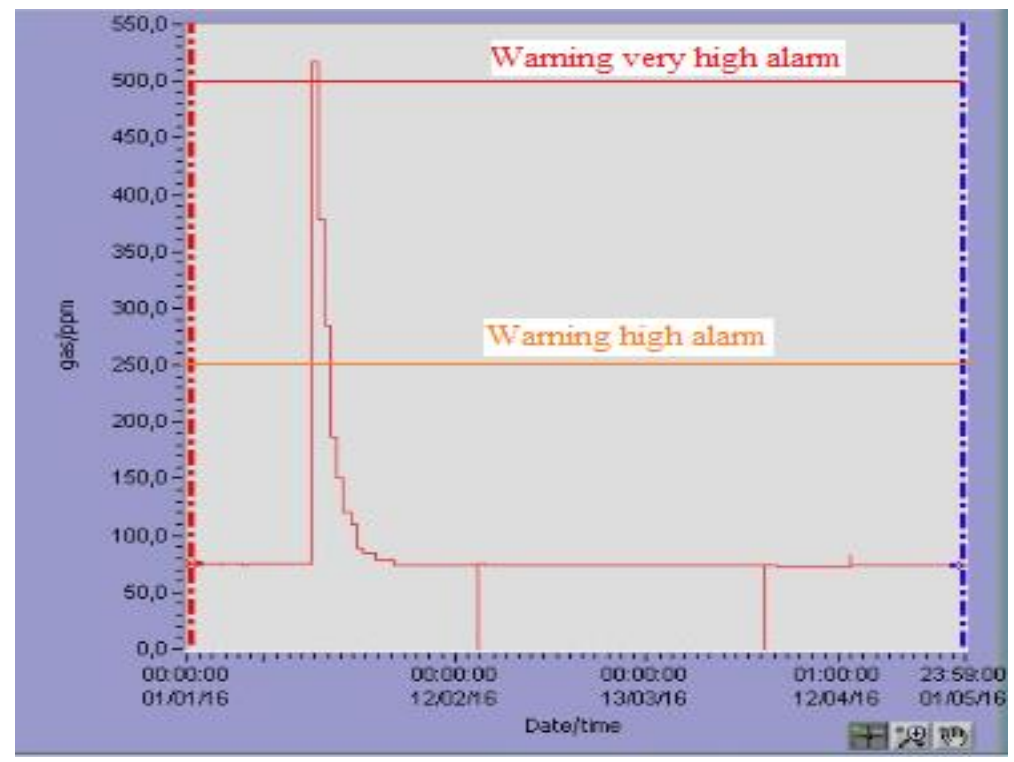

Figure 4. The trend of gas in oil of power transformer 300 MVA at SS Ferizaj 2 400/110 kV (01/01/2016 $01 / 05 / 2015)$

\subsection{Partial Discharge Monitoring}

Most incipient dielectric failures will generate numerous partial discharges before the electrical failure; therefore, measurement of partial discharges is an effective method to detect a pending failure in the electrical system [16].

In Figure 5 is depicted the trends of partial discharge (phase1, phase 2 and phase 3 ) in power transformer 300 MVA at SS Ferizaj 2 400/110 kV (01/08/2015 - 07/08/2015).

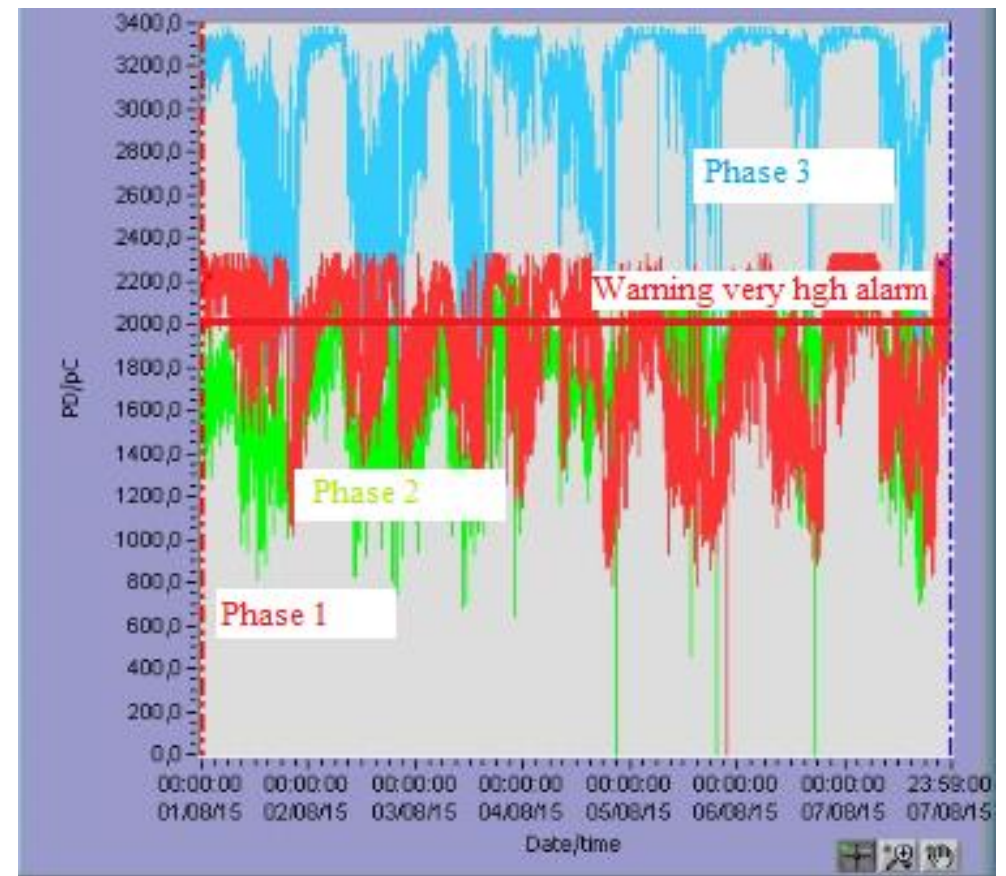

Figure 5. The trend of partial discharge (phase1, phase 2 and phase 3) in power transformer 300 MVA at SS Ferizaj 2 400/110 kV(01/08/2015-07/08/2015)

By the monitoring during this time period can be concluded that the highest volume of partial discharge is in the third phase and first phase, where the limit of $2000 \mathrm{pC}$ is exceeded. 


\subsection{Moisture Monitoring}

In a transformer, always remains a little of the water that can be residual moisture not extracted during the transformer drying in the factory before energized, water ingressed from the atmosphere, and aging water generated in the decomposition reactions of cellulose and oil [17]. The humidity trend is depicted in Figure 6, which shows the online condition of moisture on paper and its level in the transformer. From the monitoring it can be seen that there are changes in periods, respectively, in the period time during September 2015, the first and second level of humidity on paper has been exceeded by $3 \mathrm{ppm}$, respectively $5 \mathrm{ppm}$. Moisture monitoring is also important because it shows the continuity of the condition of the impregnated transformer paper. In Figure 6 are presented the trends of moisture in the paper bottom in power transformer 300 MVA at SS Ferizaj 2 400/110 kV (01/09/2015 - 30/09/2015).

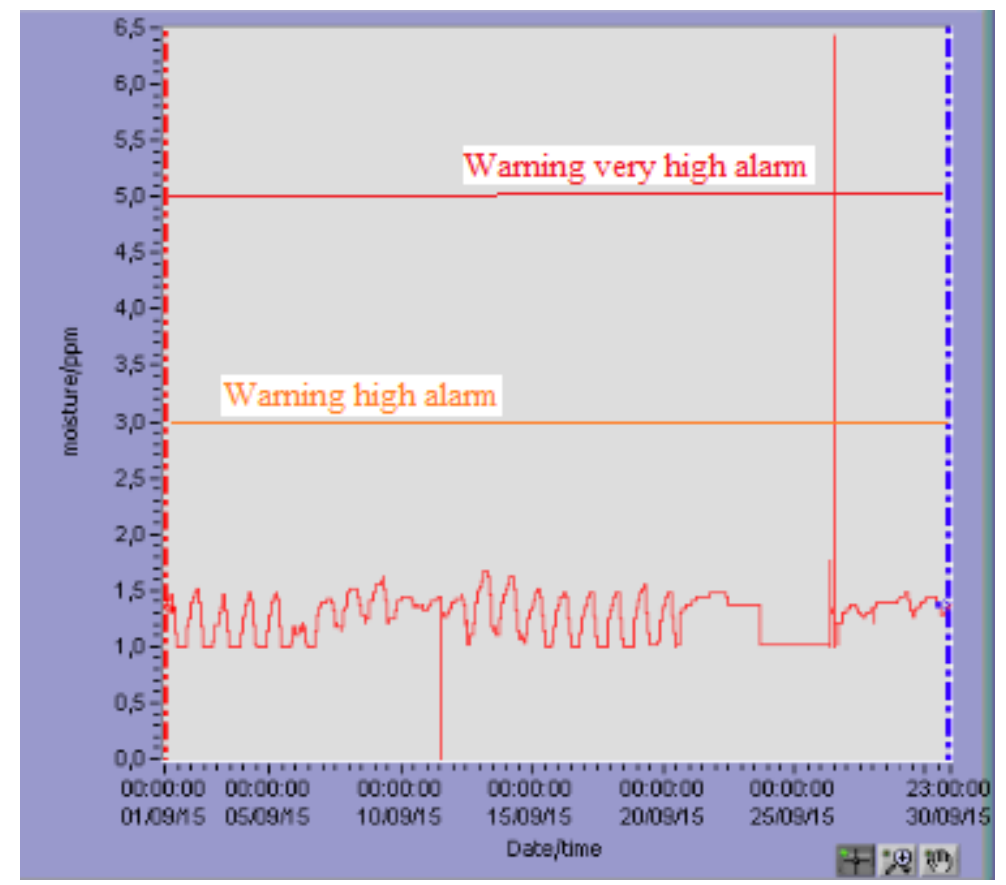

Figure 6. The trend of moisture in the paper bottom in power transformer 300 MVA at SS Ferizaj 2 400/110 kV $(01 / 09 / 2015-30 / 09 / 2015)$

\subsection{Tap Changer}

Tap-changers are considered as electro-mechanical switching equipment operating within tap-changing positions of power transformers. The operational principle of tap changers is based on a sequence of switching events within certain timing intervals depend on voltage fluctuations, optimization processes, overhead power lines synchronization, and other load conditions in the power system. This operation carries out by changing the transformer ratio using tapped windings to compensate variations of the voltages and loads. Also, this parameter is significant to minimize the number of power system outages and load interruptions. Based on statistics and surveys, tap changers are considered as the key factors in the majority of transformer failures [18].

Therefore, many faults and failures are due to the operational tap of the changer in the winding of the transformer. In Figure 7 are shown the trends of tap changer temperature in power transformer 300 MVA at SS Ferizaj $2400 / 110 \mathrm{kV}(01 / 08 / 2015-30 / 08 / 2015)$.

The tap changer operation is a considerable indicator for the operation of the transformer and that is in the function of the load changes and voltage optimization in the power system, whether in the transmission or distribution system. According to statistics, one of the factors that affect the longevity and reliability of transformers is the tap changer. 


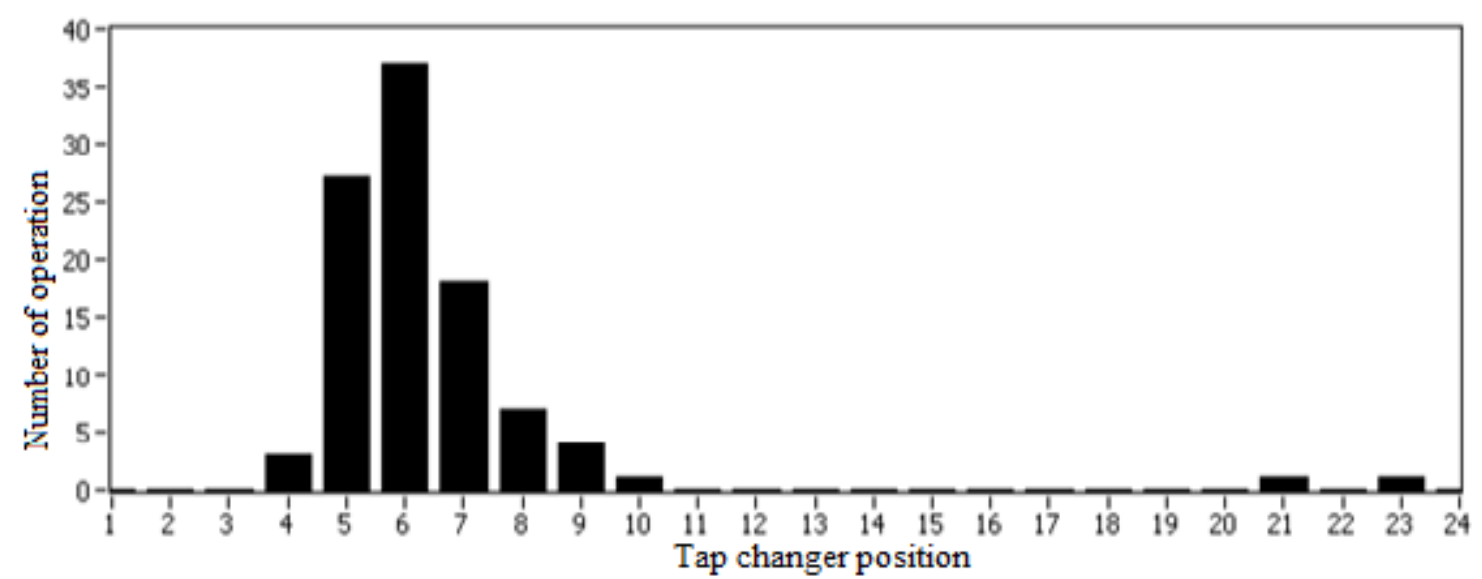

Figure 7. The trend of tap changer temperature in power transformer 300 MVA at SS Ferizaj 2 400/110 kV (01/08/2015-30/08/2015)

The trend of monitoring the operation of transformer positions is shown in Figure 7, where it is seen that positions 6, 5 and 7 are most affected in their operation according to the time depicted in the Figure 7. Therefore, monitoring the transformer winding positions is a necessary condition in timely maintenance and intervention, so that the operation is according to the standards and duration of their work.

\subsection{Bushing Monitoring}

Bushing are subjected to high dielectric and thermal stresses; in this context, bushing failures are one of the main causes of forced outages and transformer failures and contribute approximately to about $20 \%$. The failures in the winding are often emitting partial discharges and can be a result of transient overvoltages from short circuits and other disturbances in the electrical grid. Thus, a monitoring system for the bushing's capacitance and dissipation factor, partial discharges, and grid transients will reduce the failure probability in some parts of the power transformers [19].

In Figure 8 is shown monitoring of power transformer current at bushings (side of $110 \mathrm{kV}$ of power transformer 300 MVA at SS Ferizaj 2 400/110 kV.

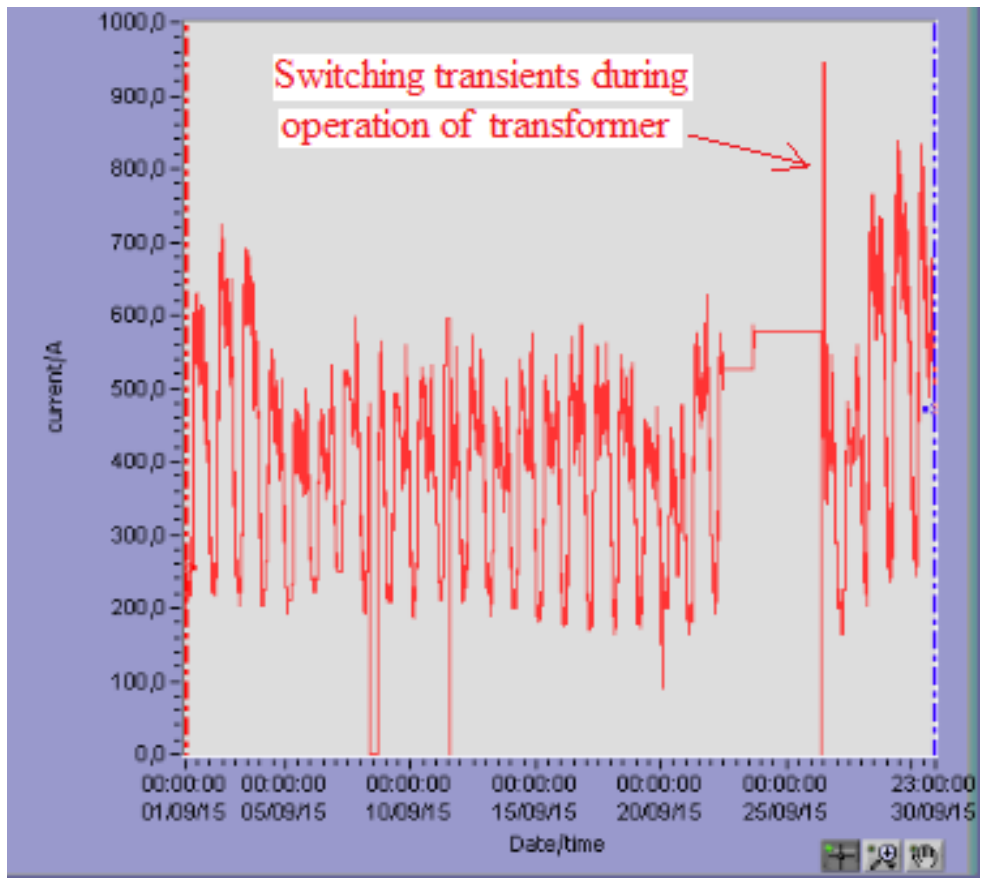

Figure 8. Monitoring of power transformer current at bushings (side of $110 \mathrm{kV}$ of power transformer $300 \mathrm{MVA}$ at SS Ferizaj 2400/110 kV 
Figure 8, respectively in the period time $01 / 09 / 2015$ - 30/09/2015, shows the monitoring of the current trend in one phase on the $110 \mathrm{kV}$ side of the power transformer, which also shows the transitions during switching voltages. Thus, such an overview of the trend of parameters in the bushing and in this case of current transitions helps in structuring possible analyzes and defects, as well as in maintaining transient stability, and in more severe cases of a dynamic one.

\section{ONLINE MONITORING OF POWER TRANSFORMER PARAMETERS}

Alarms and monitoring trends within the present state of continual performance power transformers, where through various alarms and signals help operators and experts on the state and operation of the transformer. However, this helps in covering different issues online as well as preventing possible defects, and the safety of transformers. In Table 1 is presented a report in the respective period time in power transformers 300MVA at SS Ferizaj 2, which is monitored by Koncar platform. This is an advanced way of constructing a general data structure that helps in analyzing and finding the operating diagnostics of transformer parameters.

Table1. Report of monitoring parameters in power transformer $300 \mathrm{MVA}$ at SS Ferizaj 2 400/110 kV

\begin{tabular}{|c|c|c|c|c|c|c|c|c|c|}
\hline \multirow[t]{3}{*}{ Signal } & \multicolumn{5}{|c|}{ Scale settings } & \multicolumn{4}{|c|}{ Alarm limits settings } \\
\hline & \multicolumn{2}{|c|}{ Raw } & \multicolumn{2}{|c|}{ Eng } & \multirow[t]{2}{*}{ Deadband } & \multirow[t]{2}{*}{ LoLo } & \multirow[t]{2}{*}{ Lo } & \multirow[t]{2}{*}{$\mathrm{Hi}$} & \multirow[t]{2}{*}{$\mathrm{HiHi}$} \\
\hline & Min & Max & Min & Max & & & & & \\
\hline TMS Cubicle Temperature & -50.00 & 200.00 & $-50.00^{\circ} \mathrm{C}$ & $200.00^{\circ} \mathrm{C}$ & $0.40 \%$ & $-30^{\circ} \mathrm{C}$ & $-25^{\circ} \mathrm{C}$ & $50^{\circ} \mathrm{C}$ & $60^{\circ} \mathrm{C}$ \\
\hline temperature bubbling* & - & - & $0.00 \mathrm{~K}$ & $250.00 \mathrm{~K}$ & $0.40 \%$ & & & & \\
\hline temperature bubbling margine* & - & - & $0.00 \mathrm{~K}$ & $250.00 \mathrm{~K}$ & $0.40 \%$ & $20 \mathrm{~K}$ & - & - & - \\
\hline Moisture in Paper Top* & - & - & $0.00 \mathrm{ppm}$ & $100.00 \mathrm{ppm}$ & $0.01 \%$ & - & - & $3 \mathrm{ppm}$ & $5 \mathrm{ppm}$ \\
\hline Moisture in Paper Hot Spot* & - & - & $0.00 \mathrm{ppm}$ & $100.00 \mathrm{ppm}$ & $0.01 \%$ & - & - & $3 \mathrm{ppm}$ & $5 \mathrm{ppm}$ \\
\hline Moisture in Paper Bottom* & - & - & $0.00 \mathrm{ppm}$ & $100.00 \mathrm{ppm}$ & $0.01 \%$ & - & - & $3 \mathrm{ppm}$ & $5 \mathrm{ppm}$ \\
\hline Ageing Rate* & - & - & 0.00 & 2.00 & $0.01 \%$ & & & & \\
\hline Residual Lifetime* & - & - & 0.00 years & 30.00 years & $0.00 \%$ & $\begin{array}{c}0 \\
\text { years }\end{array}$ & $\begin{array}{c}1 \\
\text { years }\end{array}$ & - & - \\
\hline 1R NQS & - & - & $0.00 \mathrm{pA}$ & $5000.00 \mathrm{pA}$ & $0.02 \%$ & & & & \\
\hline $1 Y$ NQS & - & - & $0.00 \mathrm{pA}$ & $5000.00 \mathrm{pA}$ & $0.02 \%$ & & & & \\
\hline 1B NQS & - & - & $5000.00 \mathrm{pA}$ & $0.00 \mathrm{pA}$ & $-0.02 \%$ & & & & \\
\hline 1R Charge & - & - & $0.00 \mathrm{pC}$ & 2000.00 pC & $0.05 \%$ & - & - & - & $\begin{array}{l}2000 \\
\mathrm{pC}\end{array}$ \\
\hline 1Y Charge & - & - & $0.00 \mathrm{pC}$ & $2000.00 \mathrm{pC}$ & $0.05 \%$ & - & - & - & $\begin{array}{l}2000 \\
\mathrm{pC}\end{array}$ \\
\hline 1B Charge & - & - & $0.00 \mathrm{pC}$ & $2000.00 \mathrm{pC}$ & $0.05 \%$ & - & - & - & $\begin{array}{c}2000 \\
\mathrm{pC}\end{array}$ \\
\hline SPEC Monitor WD & - & - & 0.00 & 2.00 & $0.01 \%$ & - & - & 1.9 & - \\
\hline Tap Position* & - & - & 0.00 & 1140.87 & $0.09 \%$ & & & & \\
\hline Position of Tap Over Selector* & - & - & 0.00 & 17.00 & $0.01 \%$ & & & & \\
\hline Position of Change Over Selector* & - & - & 0.00 & 17.00 & $0.01 \%$ & & & & \\
\hline Temperature in tap changer pocket & -50.00 & 200.00 & $-50.00^{\circ} \mathrm{C}$ & $200.00^{\circ} \mathrm{C}$ & $0.40 \%$ & & & & \\
\hline $\begin{array}{l}\text { Temperature difference OLTC tank } \\
\text { transformer tank* }\end{array}$ & - & - & $0.00 \mathrm{~K}$ & $100.00 \mathrm{~K}$ & $1.00 \%$ & - & - & $5 \mathrm{~K}$ & $10 \mathrm{~K}$ \\
\hline Diverter Switch Current* & - & - & $0.00 \mathrm{~A}$ & $100.00 \mathrm{~A}$ & $1.00 \%$ & & & & \\
\hline Sum of Switched Current* & - & - & $0.00 \mathrm{kA}$ & $100.00 \mathrm{kA}$ & $0.10 \%$ & & & & \\
\hline Number of Selector Operations* & - & - & 0.00 & 100.00 & $0.01 \%$ & & & & \\
\hline No. preselector operations* & - & - & 0.00 & 100.00 & $0.01 \%$ & & & & \\
\hline Service life* & - & - & 0.00 & 100.00 & $0.00 \%$ & & & & \\
\hline Duration of Switching Operation* & - & - & $0.00 \mathrm{~s}$ & $100.00 \mathrm{~s}$ & $0.01 \%$ & - & - & $30 \mathrm{~s}$ & $60 \mathrm{~s}$ \\
\hline
\end{tabular}

\section{CONCLUSIONS}

Thus, the paper shows the relevant monitoring data in the online format of performing electrical and thermal parameters, through which the performance of the transformer operation in different conditions and periods is described. From this, it can be concluded that in some cases there is an excess of the 
operating limits of the parameters, such as temperature, gases, transient processes, etc. This enables a more efficient diagnosis for transformers and responsible engineers.

Given the importance of the work of power transformers in the electricity system, including online operation and safety aspect that comes into account the advancement of technology so that it becomes possible installation monitoring modules which play a role in the provision of online data of transformer work. It has advanced at high performance and operational continuity in the power system. So, by day and obligations within the ENTSO-E to broadcasters as well as obligations under customer supply without interruption, monitoring has great importance to the proper functioning and prior notification of problems in the power transformers. So, seeing the trend of development and operation of parameters in the most important parts of the power transformer, much clearer and preventive results are achieved for the maintenance and proper operation of the transformer. Among other things, through the online monitoring method built according to smart and advanced systems, predictions can be made in the work of power transformers parameters and a more realistic picture of their condition can be built and preliminary concepts for thorough engineering interventions and analyzes can be prepared. It also helps increase the reliability and lifespan of transformers and the power system in general.

However, the online monitoring of transformers is an aid for engineers to build a platform for the specific diagnosis of transformers, in order to have a summary of their operational performance. It is also recommended that other papers take into account aspects of the operation of intelligent data processing equipment, in terms of the appearance of the most vital parts of transformers and the accuracy of parameter estimation.

\section{REFERENCES}

[1] Eroğlu, Y., Ulusam Seçkiner, S., Early fault prediction of a wind turbine using a novel ANN training algorithm based on ant colony optimization. Journal of Energy Systems 2019, 3(4), 139-147, DOI: 10.30521/jes.613315.

[2] Cardillo, E. and Feser, K., New approach in thermal monitoring of large power transformers applied on a 350 MVA odaf-cooled unit. Prace Naukowe Instytutu Podstaw Elektrotechniki i Elektrotechnologii Politechniki Wroctawskiej. Konferencje, 2004, 40(15), 77-81.

[3] Osztermayer J, Cardillo E, Markalous SM, Wimmer R, Lenz M, Hoek SM, Feser K. Asset management based on improved online monitoring systems applied to a 110/380 kV substation. In2003 IEEE Bologna Power Tech Conference Proceedings; 23-26 June 2003: IEEE, Italy: pp. 5.

[4] Stirl T, Skrzypek R, Tenbohlen S, Vilaithong R. Online condition monitoring and diagnosis for power transformers their bushings, tap changer and insulation system, InCMD2006 Conference, 2007 Apr 1. 35(s): pp. 196-206.

[5] Petkova N, Mladenov V, Tsolov A, Nakov P, Bozukov G. Study and analysis of systems for monitoring in power substations. In Proceedings of the 15th WSEAS international conference on Systems. 14 Jul 2011: WSEAS, pp. 402-404.

[6] Chakravorti S, Dey D, Chatterjee B. Recent Trends in the Condition Monitoring of Transformers: Theory, Implementation and Analysis, 2013, London UK: Springer Science \& Business Media

[7] Rexhepi, V, Nakov, P. Condition assessment of power transformers status based on moisture level using fuzzy logic techniques. Journal of Mechatronics, Electrical Power, and Vehicular Technology, 2018, 9(1), 17-24.

[8] Banović M, Keitoue S. Mobility support for the access to a monitoring system. InIMEKO XVIII World Congres, Metrology for a Sustainable Development. 17 - 22 September 2006. IMEKO, Rio de Janeiro, Brazil, pp. 17 22.

[9] Hulaj, A., Shehu, A. and Bajrami, X., Removal of various noises from digital images with the application of a single algorithm. Int. J. Civil Eng. Technol. 2017, 8, 804-816.

[10] Hulaj A, Shehu A. An Efficient Algorithm to Energy Savings for Application to the Wireless Multimedia Sensor Networks. International Conference on Emerging Internetworking, Data \& Web Technologies 2018 Mar 15 (pp. 349-358). Springer, Cham.

[11] Tenbohlen S, Stirl T, Rosner M. Benefit of sensors for on-line monitoring systems for power transformers: Les matériels électriques de poste. REE. Revue de l'électricité et de l'électronique. 2003,10, 60-65.

[12] Rexhepi, V. and Nakov, P. Reliability indicators and condition monitoring of power transformers - Case study. Journal of Sustainable Energy, 2018, 9(1), 6-15. 
[13] Sumereder, C., Muhr, M. and Körbler, B., Lifetime management of power transformers. e \& i Elektrotechnik und Informationstechnik 2003, 12, 420-423. DOI: 10.1007/BF03053972

[14] Hurezeanu I, Nicola CI, Sacerdoţianu D, Nicola M, Aciu AM, Niţu MC. Temperature control and monitoring system for power transformer windings using fiber optic sensors. In2016 International Symposium on Fundamentals of Electrical Engineering (ISFEE) 2016 Jun 30 (pp. 1-4). IEEE.

[15] Făgărăşan I., Costinas S., Iliescu SS., Monitoring and diagnosis methods for high voltage: Power transformers. U.P.B. Sci. Bull. Series C, 2008, 70(3), 321

[16] Sikorski, W., Walczak, K., \& Przybylek, P. Moisture migration in an oil-paper insulation system in relation to online partial discharge monitoring of power transformers. Energies, 2016, 9(12), 1082. DOI: 10.3390/en9121082

[17] García B, Burgos JC, Alonso ÁM, Sanz J. A moisture-in-oil model for power transformer monitoring-Part II: Experimental verification. IEEE Transactions on Power Delivery, 2005, 20(2), 1423-1429.

[18] Feizifar B, Usta O. A new arc-based model and condition monitoring algorithm for on-load tap-changers. Electric Power Systems Research, 2019, 167, 58-70.

[19] Koch M, Krüger M. A new method for on-line monitoring of bushings and partial discharges of power transformers. IEEE International Conference on Condition Monitoring and Diagnosis; 23-27 Sept. 2012: IEEE, pp. 1205-1208. DOI 10.1109/CMD.2012.6416378. 